\title{
Antifungal activity of the essential oil from Artemisia santonicum and its constituent isogeranic acid
}

\author{
Jovana Stanković Jeremić ${ }^{*}$, Miroslav Novaković ${ }^{1}$, Vele Tešević ${ }^{2}$, Ana Ćırić ${ }^{3}$, Gordana \\ Zdunić $^{4}$, Zora Dajić Stevanović ${ }^{5}$, And DeJan GoĐevac ${ }^{1}$ \\ ${ }^{1}$ University of Belgrade, Institute of Chemistry, Technology and Metallurgy, Department of Chemistry, Njegoseva 12, 11000 Belgrade, Serbia \\ ${ }^{2}$ University of Belgrade, Faculty of Chemistry, Studentski trg 16, 11000 Belgrade, Serbia \\ ${ }^{3}$ University of Belgrade, Institute for Biological Research "Siniša Stanković", Department of Plant Physiology, Boulevard Despota Stefana 142, 11000 \\ Belgrade, Serbia \\ ${ }^{4}$ Institute for Medicinal Plant Research "Dr. Josif Pančić", Tadeuša Košćuška 1, 11000 Belgrade, Serbia \\ ${ }^{5}$ University of Belgrade, Faculty of Agriculture, Nemanjina Street 6, 11080 Zemun, Serbia \\ *Corresponding author: jovanas@chem.bg.ac.rs
}

Received: May 5, 2020

Accepted: December 16, 2020

Published on-line: December 20, 2020

Published: December 25, 2020

\begin{abstract}
This study represents a continuation of exploring of the biological activities of the Artemisia santonicum essential oil. The previous investigation was focused on the antibacterial, antibiofilm, and antiquorum activities of $A$. santonicum essential oil and isogeranic acid as the main antibacterial constituent. The present study describes its antifungal activity. The antifungal activity of the $A$. santonicum essential oil was tested against eight fungi isolates, whereas antifungal effects of isogeranic acid were studied using four fungi species, because of the limited quantities of the isolated compound. The results were compared to the commercial antimycotics, bifonazole and ketoconazole. Antifungal activity of isogeranic acid against all tested fungi was significantly higher in comparison to the essential oil and the both controls.
\end{abstract}

Key words: antifungal activity, essential oil, isogeranic acid

http://dx.doi.org/10.5937/leksir2040062S

\section{INTRODUCTION}

Artemisia santonicum, also known as "saline wormwood" is the perennial bushy herb able to form its own saline steppe vegetation type (Dajić Stevanović et al., 2016) (Figure 1). The species grows on dry and alkaline places and deserts, with preference of conditions of increased soil salinity. Apart from habitats of the central and southeast Europe, the species occurs in the Caspian region, in the mid Asia towards Mongolia. In Serbia, A. santonicum was recorded only in the northern part of the country, in the Vojvodina province, within mosaic-form patches exposed to increased soil pH and salinity (Gajić, 1975) The chemical composition of essential oils (EOs) of the genus Artemisia was investigated for several species of different distribution and varied among the species. In some cases, the variations in chemical composition of the volatiles of EO were a consequence of different collecting time, i.e. were ontogenesis-dependent. In addition to collecting period, the quality of EO was affected by genotypic variations, plant part used, and the habitat conditions, mainly soil $\mathrm{pH}$. The applied agricultural and postharvest practices, such as fertilization and drying conditions, as well as the applied extraction method, have all affected the EO composition (Abad et al., 2012). In the previous investigations on the A. santonicum $\mathrm{EO}$, different compounds were reported as the most dominant: camphor $(18.2 \%), 1,8$-cineole $(7.5 \%), \alpha$-terpineol $(4.1 \%)$ and borneol $(4.0 \%)$ (i.e. oxygenated monoterpenes (50.9\%) (Kordali et al., $2005 a), \alpha$-thujone $(44.8 \%$ ) (Badea and Delian, 2014), and camphor $(20.11 \%)$, cis-verbenol (19.85\%) and eucalyptol (18.26 $\%$ ) (Burzo et al., 2008). Some other species of the Artemisia genus exhibited similar EO chemical profiles, regarding to the presence of its main constituents. For example, in $A$. distans (Konakchiev et al., 2011) 1,8-cineole (16.8\%), $\beta$-thujone (9.8\%), sabinene $(8.2 \%)$, borneol $(7.5 \%), \beta$-pinene $(6.5 \%)$ and camphor (5.8\%) were found; high content of 1,8-cineole (21.5-27.6 $\%$ ) and camphor (15.9-37.3\%) was found in A. cana, A. frigida, A. longifolia and A. ludoviciana (Lopes-Lutz et al., 2008). Additionally, the major compounds in $\mathrm{EO}$ of $A$. gorgonum were camphor $(28.7 \%)$ and chrysanthenone $(10.8 \%)$ (Ortet et al., 2010), whereas in A. fragans, chrysanthenone (23.8 \%), and 1,8-cineole $(23.7 \%)$ were the most dominant (Shafaghat et al., 2009). There are numerous reports about biological activities of different Artemisia species such as antioxidant, antibacterial, antifungal, antimalarial, and antidiabetic activity (Dadasoglu et al., 2015). Additionally, EO of $A$. santonicum, together with selected extracts, was investigated on selected enzymes (cholinesterase, tyrosinase $\alpha$-amylase, and $\alpha$-glucosidase) as 


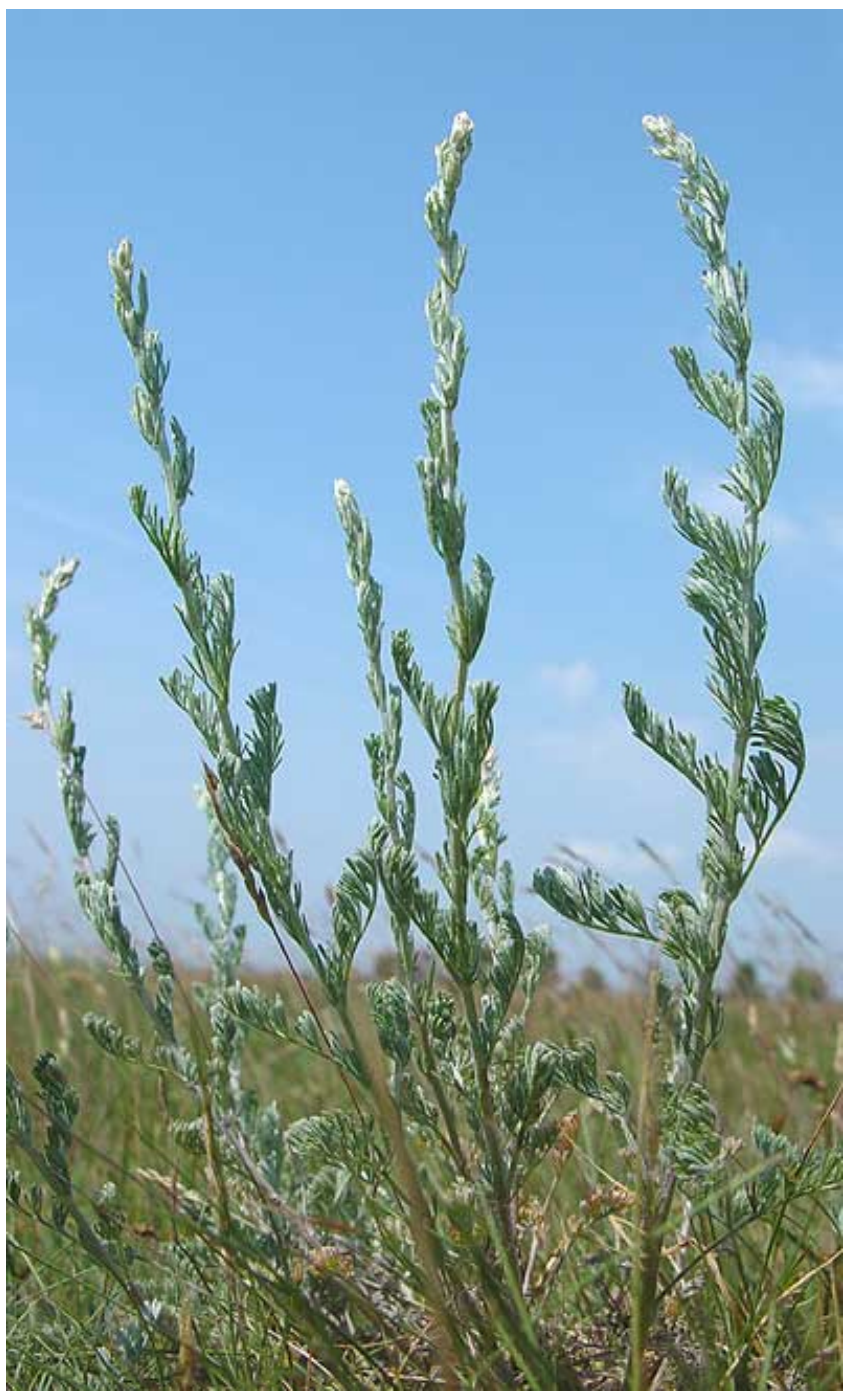

Fig. 1. Artemisia santonicum L. (Slano Kopovo, july 2016.)

well as their antioxidant and pharmacological effects (Ferrante et al., 2019). The aim of the present investigation was to determine the potential antifungal activity of the A. santonicum EO and of its individual component, isogeranic acid (IA) as a continuation of the previous work and antibacterial investigation (Stanković et al., 2019).

\section{MATERIALS AND METHODS}

\subsection{Plant material, isolation and chemical analysis of the essential oil}

The data about plant material, isolation of the A. santonicum EO and its chemical analysis were described in the previous study of Stanković et al. (2019).

\subsection{Isolation and identification of isogeranic acid}

The $A$. santonicum $\mathrm{EO}$ fractionation, isolation of isogeranic acid and structure elucidation were also described in the previous study of Stanković et al. (2019).

\subsection{Antifungal activity of the essential oil and isogeranic acid}

Antifungal activity of the EO was studied using the following fungal species: Aspergillus niger (ATCC 6275), Aspergillus ochraceus (ATCC 12066), Aspergillus fumigates (ATCC 9197), Aspergillus versicolor (ATCC 11730), Penicillium funiculosum (ATCC 36839), Penicillium ochrochloron (ATCC 9112), Trichoderma viride (IAM 5061) and Penicillium verrucosum var. cyclopium (food isolate). Only four fungal species A. niger, A. fumigatus, $P$. ochrochloron and $P$. verrucosum were selected for the antifungal activity of IA. The reason was the limited quantity of isolated IA. The selection of particular fungi was made upon previous information on their high sensitivity to IA. Fungal species were obtained from the Mycological Laboratory, Department of Plant Physiology, Institute for Biological Research "Siniša Stankovic", Belgrade, Serbia. The micromycetes were maintained on malt agar and the cultures stored at $4{ }^{\circ} \mathrm{C}$ and sub-cultured once a month (Booth, 1971). The antifungal assay was carried out by modified microdilution method (Espinel-Ingroff, 2001) using procedure described by Rashed et al. (2014). Ranges of concentrations of the $\mathrm{EO}$ and IA were 3-12 and 0.05-0.075 mg/mL, respectively. The fungicides bifonazole and ketoconazole were used as positive controls (1-3500 $\mathrm{g} / \mathrm{mL}$ ). Three independent experiments were performed in duplicate.

\section{RESULTS AND DISCUSSION}

In the previous investigation, the chemical composition of the $\mathrm{EO}$ isolated from the aerial parts of $A$. santonicum was established by GC-MS/FID and 75 components were identified (Stanković et al., 2019). The major group consisted of the oxygenated monoterpenes $(67.5 \%)$ and the most abundant compounds were 1,8-cineole $(18.8 \%)$, chrysanthenone (13.3 $\%)$, cis-thujone $(8.4 \%)$, trans-sabinyl acetate $(3.3 \%)$, camphor $(3.0 \%)$ and trans-sabinol (2.9\%). In addition to the oxygenated monoterpenes, the monoterpene hydrocarbons accounted for $8.2 \%$, sesquiterpene hydrocarbons participated with $5.6 \%$, oxygenated sesquiterpenes with $3.3 \%$, whereas normonoterpenes, homomonoterpenes and aromatics with $2.6 \%, 1.0 \%$ and $1.9 \%$, respectively.

The antifungal activity of the EO, IA and known antimycotics bifonazole and ketoconazole used as controls are presented in Table 1 and Figure 2. So far, the antifungal activity of $A$. santonicum $\mathrm{EO}$ was tested against $A$. niger only, and moderate activity was determined (Kordali et al., 2005b). This study represents the first report on antifungal activity of $A$. santonicum EO against $A$. ochraceus, $A$. fumigates, $A$. versicolor, $P$. funiculosum, P. ochrochloron, T. viride and P. verrucous. EO showed moderate antifungal activity in the range of 3-12 $\mathrm{mg} / \mathrm{mL}$ for MIC, with the most pronounced effect on A. ochraceus, T. viride, $P$. funiculosum and P. verrucosum. Compared to bifonazole and ketoconazole, known antifungal standards, EO exhibited lower activity. Pure IA exhibited strong antifungal activity against tested fungi. MIC for $A$. fumigatus and $P$. ochrochloron was $0.05 \mathrm{mg} / \mathrm{mL}$ and for $A$. niger and P. verrucosum was 0.075 $\mathrm{mg} / \mathrm{mL}$. IA exhibited stronger antifungal activity not only compared to the EO, but also higher than the both antimycotic standards, bifonazole and ketoconazole (in most cases 2-4 times, Figure 2). These results are in agreement with the findings of Kordali et al. (2005a) that the main components, camphor and 1,8-cineole, are not responsible for the antifungal activity of Artemisia oils and that antifungal activity of these oils can be attributed to some minor components, like IA. In the previous studies on antifungal activity of the $A$. santonicum EO, Kordali et al. (2005a) reported the chemical composition, antifungal and antibacterial activities of the $\mathrm{EO}$ obtained from four Turkish Artemisia species, A. dracunculus, $A$. absinthium, A. santonicum and $A$. spicigera. The main components of these EOs were camphor (1.4-34.9\%), 1,8-cineole (1.5-9.5\%), chamazulene (n.d.-17.8\%), nuciferol propionate (n.d.-5.1\%), nuciferol butanoate (n.d.-8.2\%), caryophyllene oxide (1.7-4.3\%), etc. The antifungal activities of these EOs were tested against eleven plant fungi, compared to commercial antimycotic benomyl, and the results showed that all tested oils have potent inhibitory effects against almost all of the tested fungi. Pure camphor and 1,8-cineole, which are the major components of the oils, showed antifungal activity against some of 
Table 1. Minimum inhibitory (MIC) and fungicidal concentration (MFC) of Artemisia santonicum essential oil, isogeranic acid and commercial antibiotics

\begin{tabular}{|c|c|c|c|c|c|}
\hline Fungi & Method & $\begin{array}{r}\text { Essential oil } \\
{[\mathrm{mg} / \mathrm{mL}]}\end{array}$ & $\begin{array}{r}\text { Isogeranic acid } \\
{[\mathrm{mg} / \mathrm{mL}]}\end{array}$ & $\begin{array}{r}\text { Bifonazole } \\
{[\mathrm{mg} / \mathrm{mL}]}\end{array}$ & $\begin{array}{r}\text { Ketoconazole } \\
{[\mathrm{mg} / \mathrm{mL}]}\end{array}$ \\
\hline \multirow[t]{2}{*}{ Aspergillus fumigatus } & MIC & $6 \pm 0.3$ & 0.05 & $0.15 \pm 0.004$ & $0.20 \pm 0.006$ \\
\hline & MFC & $12 \pm 0.2$ & 0.1 & $0.20 \pm 0.005$ & $0.50 \pm 0.005$ \\
\hline \multirow[t]{2}{*}{ Aspergillus versicolor } & MIC & $6 \pm 0.3$ & - & $0.10 \pm 0.006$ & $0.20 \pm 0.003$ \\
\hline & MFC & $12 \pm 0.4$ & - & $0.20 \pm 0.005$ & $0.50 \pm 0.005$ \\
\hline \multirow[t]{2}{*}{ Aspergillus ochraceus } & MIC & $3 \pm 0.6$ & - & $0.15 \pm 0.008$ & $1.50 \pm 0.050$ \\
\hline & MFC & $6 \pm 0,5$ & - & $0.20 \pm 0.009$ & $2.00 \pm 0.060$ \\
\hline \multirow[t]{2}{*}{ Aspergillus niger } & MIC & $12 \pm 3$ & 0.075 & $0.15 \pm 0.006$ & $0.20 \pm 0.004$ \\
\hline & MFC & $25 \pm 4$ & 0.1 & $0.20 \pm 0.007$ & $0.50 \pm 0.006$ \\
\hline \multirow[t]{2}{*}{ Trichoderma viride } & MIC & $3 \pm 0.4$ & - & $0.15 \pm 0.009$ & $1.00 \pm 0.050$ \\
\hline & MFC & $6 \pm 0.6$ & - & $0.20 \pm 0.003$ & $1.00 \pm 0.060$ \\
\hline \multirow[t]{2}{*}{ Penicillium funiculosum } & MIC & $3 \pm 0.3$ & - & $0.20 \pm 0.004$ & $0.20 \pm 0.004$ \\
\hline & MFC & $9 \pm 0.4$ & - & $0.25 \pm 0.005$ & $0.50 \pm 0.003$ \\
\hline \multirow[t]{2}{*}{ Penicillium ochrochloron } & MIC & $5 \pm 0.8$ & 0.05 & $0.20 \pm 0.006$ & $2.50 \pm 0.200$ \\
\hline & MFC & $6 \pm 0.6$ & 0.1 & $0.25 \pm 0.006$ & $3.50 \pm 0.300$ \\
\hline \multirow[t]{2}{*}{ Penicillium verrucosum } & MIC & $3 \pm 0.2$ & 0.075 & $0.10 \pm 0.006$ & $0.20 \pm 0.005$ \\
\hline & MFC & $9 \pm 0.3$ & 0.1 & $0.20 \pm 0.008$ & $0.30 \pm 0.003$ \\
\hline
\end{tabular}
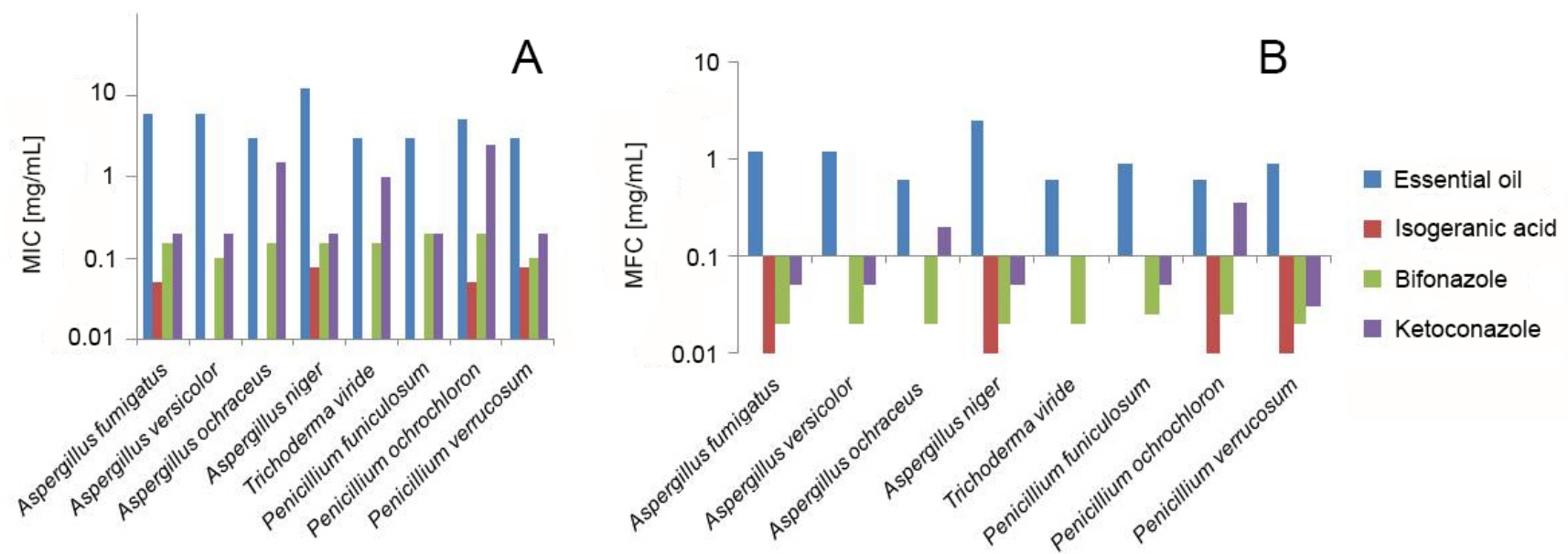

Fig. 2. Minimum inhibitory (A) and fungicidal concentration (B) of A. santonicum essential oil, isogeranic acid, bifonazole and ketoconazole.

the fungal species and had weaker effects than essential oils of investigated Artemisia species (Kordali et al., 2005a) showing that antifungal activity of the oil do not arise only from the main constituents.

In further investigation, antibacterial and antifungal activities of the EOs isolated from A. dracunculus, A. absinthium, A. santonicum, and $A$. spicigera, the antifungal activity was tested against 34 fungal species revealing the potent antifungal activity, similar to effects of the standard antimycotic compound, benomyl. Among the tested oils, the weakest antifungal activity showed the EO of the $A$. dracunculus. In most cases, the oils of $A$. absinthium, A. santonicum, and A. spicigera completely inhibited the growth of some fungal species (Kordali et al., 2005b). In the work of Badea and Delian (2014), EOs of ten Artemisia species including $A$. santonicum, were studied against fungal pathogen Sclerotinia sclerotiorum. In conclusion of this investigation, Artemisia oils exhibited significant activity and were proposed for use as botanical fungicides and green pesticides (Badea and Delian, 2014).

At the end, after checking all of the literature data, antifungal activity of $A$. santonicum against seven not investigated fun- gal strains up to now was here confirmed, fulfilling present antifungal data of the $A$. santonicum EO. Isogeranic acid was found for the first time in these oils and its strong antifungal activity against four fungal strains was reported for the first time. According to these results, an extended investigation of the antifungal activity of this compound is needed.

\section{CONCLUSION}

In this work, the antifungal activity of $A$. santonicum essential oil and isogeranic acid as an active component is presented. For the first time, the antifungal activity of $A$. santonicum essential oil was investigated against $A$. ochraceus, $A$. fumigates, A. versicolor, $P$. funiculosum, $P$. ochrochloron, T. viride and $P$. verrucous. The essential oil showed moderate antifungal activity, whereas isogeranic acid, which is present in essential oil in small quantity of only $0.2 \%$, exhibited strong antifungal action against $A$. fumigatus, $P$. ochrochloron, $A$. niger and $P$. verrucosum. Moreover, isogeranic acid showed 2-4 times stronger effects than both antimycotic standards bifonazole and ketoconazole. These results suggest that minor components, like isogeranic 
acid, might be responsible for the antifungal activity, and further research on its biological activity and mechanisms of antifungal action could be recommended.

\section{ACKNOWLEDGMENTS}

This work was financially supported by the Ministry of Education, Science and Technological Development of the Republic of Serbia (Grant No. 451-03-68/2020-14/200026).

\section{REFERENCES}

Abad, M. J., Bedoya, L. M., Apaza, L. and Bermejo, P. (2012). The Artemisia L. genus: a review of bioactive essential oils, Molecules (Basel, Switzerland) 17(3): 2542-2566.

Badea, M. L. and Delian, E. (2014). In vitro antifungal activity of the essential oils from Artemisia spp. L. on Sclerotinia sclerotiorum., Romanian Biotechnological Letters 19(3): 93459352.

Booth, C. (1971). Fungal culture media, in J. Norris and D. Ribbons (eds), Methods in microbiology, Academic Press, London.

Burzo, I., Ciocârlan, V., Delian, E., Dobrescu, A. and Bădulescu, L. (2008). Researches regarding the essential oil composition of some Artemisia 1. species, Scientific Annals of „Alexandru Ioan Cuza", University of Iasi, New Series, Section II a. Vegetal Biology 54(2): 86-91.

Dadasoglu, F., Kotan, R., Cakir, A., Cakmakci, R., Kordali, S., Ozer, H., Karagoz, K. and Dikbas, N. (2015). Antibacterial activities of essential oils, extracts and some of their major components of Artemisia spp. L. against seed-borne plant pathogenic bacteria, Fresenius Environmental Bulletin 24(9): 2715-2724.

Dajić Stevanović, Z., Aćić, S., Luković, M., Zlatković, I., Vasin, J., Topisirović, G. and Šilc, U. (2016). Classification of continental halophytic grassland vegetation of Southeastern Europe, Phytocoenologia 46(3): 317-331.

Espinel-Ingroff, A. (2001). Comparison of the E-test with the NCCLS M38-P method for antifungal susceptibility testing of common and emerging pathogenic filamentous fungi, Journal of Clinical Microbiology 39(4): 1360-1367.

Ferrante, C., Zengin, G., Menghini, L., Diuzheva, A., Jekő, J., Cziáky, Z., Recinella, L., Chiavaroli, A., Leone, S., Brunetti, L., Lobine, D., Senkardes, I., Mahomoodally, M. F. and Orlando, G. (2019). Qualitative fingerprint analysis and multidirectional assessment of different crude extracts and essential oil from wild Artemisia santonicum L., Processes 7(8): 522.

Gajić, M. (1975). Genus Artemisia, in M. Josifović (ed.), Flora of Republic of Serbia, Vol. VII, Serbian Academy of Science and Art, Belgrade, pp. 121-128.

Konakchiev, A., Todorova, M., Mikhova, B., Vitkova, A. and Najdenski, H. (2011). Composition and antimicrobial activity of Achillea distans essential oil, Natural product communications 6: 905-906.

Kordali, S., Cakir, A., Mavi, A., Kilic, H. and Yildirim, A. (2005a). Screening of chemical composition and antifungal and antioxidant activities of the essential oils from three Turkish Artemisia species, Journal of Agricultural and Food Chemistry 53(5): 1408-1416.
Kordali, S., Kotan, R., Mavi, A., Cakir, A., Ala, A. and Yildirim, A. (2005b). Determination of the chemical composition and antioxidant activity of the essential oil of Artemisia dracunculus and of the antifungal and antibacterial activities of Turkish Artemisia absinthium, A. dracunculus, Artemisia santonicum, and Artemisia spicigera essential oils, Journal of Agricultural and Food Chemistry 53(24): 9452-9458.

Lopes-Lutz, D., Alviano, D. S., Alviano, C. S. and Kolodziejczyk, P. P. (2008). Screening of chemical composition, antimicrobial and antioxidant activities of Artemisia essential oils, Phytochemistry 69(8): 1732-1738.

Ortet, R., Thomas, O., Regalado, E., Pino, J., Filippi, J.-J. and Fernández, M. (2010). Composition and biological properties of the volatile oil of Artemisia gorgonum Webb., Chemistry $\mathcal{E}$ Biodiversity 7(5): 1325-1332.

Rashed, K., Ćirić, A., Glamočlija, J., Calhelha, R. C., Ferreira, I. C. F. R. and Soković, M. (2014). Antimicrobial and cytotoxic activities of Alnus rugosa L. aerial parts and identification of the bioactive components, Industrial Crops and Products 59: $189-196$.

Shafaghat, A., Noormohammadi, Y. and Zaifizadeh, M. (2009). Composition and antibacterial activity of essential oils of Artemisia fragrans Willd. leaves and roots from Iran, Natural Product Communications 4(2): 279-282.

Stanković, J., Novaković, M., Tešević, V., Ćirić, A., Soković, M., Zdunić, G., Dajić-Stevanović, Z. and Gođevac, D. (2019). HPTLC-direct bioautography-guided isolation of isogeranic acid as the main antibacterial constituent of Artemisia santonicum essential oil, Journal of the Serbian Chemical Society 84(12): 1355-1365. 